ORIGINAL ARTICLE

\title{
Isolation and Identification of different Intestinal Helminthes Groups from Stray Cats in Urban City of Kirkuk
}

\author{
HUSAIN F. HASSAN AND SABREEN Y. GAEIB \\ Department of Biology, College of Science, University of Kirkuk \\ Email: drhusain4@gmail.com, sabrengrgr@gmail.com
}

\begin{abstract}
In this study, 25 stray cats were caught from the urban city of Kirkuk hunted using specially designed traps. Cats were dissected and examined in order to investigate its infection with intestinal parasites. Our results indicate that all stray cats were infected with at least one type of helminthes. Three types of Trematodes were identified: Echinochasmus, Heterophyes and, Prohemistomum with infection rate of $4 \%$ for each type. Such species were identified for the first time in stray cats in the Iraq. Moreover, four types of cestodes were identified: Diplopylidium, Dipylidium caninum, Joyeuxiella and Taenia taeniaeformis with infection rate of $24 \% 48 \%, 16 \%$ and $12 \%$, respectively. Nematodes of Physaloptera preputalis, Toxocara cati and Toxoascaris leonina were also found. The infection rate was $4 \%, 28 \%$ and $8 \%$ for each type, respectively.

Keywords: intestinal helminthes, stray cats, Trematodes.
\end{abstract}

\section{INTRODUCTION}

Cats are the main hosts of many parasitic organisms and are often considered as one of the most domesticated pets of humans. Therefore, transmit many internal and external parasites to him, causing various dangerous diseases (Mircean, Titilincu, \& Vasile, 2010). Toxoplasma gondii is one of the highly dangerous parasitic protozoans that invade the epithelial cells of the cat's intestines, and if they reach the fetus through the placenta of the pregnant mother, they cause abortion or congenital toxoplasmosis, and the baby will born deformed in his head (Fisher, 2003). One of the common and widespread roundworms in cat infection is Toxocara cati, whose mature eggs, if reached by food and contaminated water, can hatch in his intestines into larvae that later settle in all his organs, causing visceral larval migrans (Ma et al., 2018).

Due to both: medically paramount importance of these parasites and the lack of studies in this field, the current research aimed to study intestinal parasites in stray cats in the city of Kirkuk.

\section{MATERIALS AND METHODS}

Study area: All Samples were collected from different residential neighborhoods in the city of Kirkuk. The autopsy and isolation of parasites were carried out in the Postgraduate Parasitology Laboratories, Department of Biology, College of Science, University of Kirkuk.

Sample collection: 25 stray cats (15 males and 10 females) were caught using an iron trap $(70 \times 25 \times 25 \mathrm{~cm})$ prepared for this specific purpose. Cats were caught from randomly urban areas inside of Kirkuk city. Later on, cats were transferred to the laboratory for the purpose of autopsy. They were killed by injecting an appropriate amount of formalin (37\%) in the peritoneum area. Then, the digestive system was separated and cleaned with saline $(0.9 \%)$. All parts of the digestive system were opened separately, helminth species were isolated by examination using anatomical microscopy and compound light microscopy (M. Hadi \& Hind Abdulzahra Al, 2018).

Staining of Parasitic Helminths: The isolated specimens were investigated using compound light microscope. They were stained using Aceto-carmine and Hematin stain and pressed between two glass slides. Nematodes were further stained with Lactophenol dye for two minutes, in order to remove the excess parts and get the appropriate transparency for examination. Furthermore, such procedure will help clarifying the internal parts of Nematodes (Barbosa et al., 2015).

Cestodes were washed with $0.9 \%$ normal saline physiological solution and stored in $4 \%$ formalin solution. Later on, they were stained with Aceto-Carmine stain and pressed between two slides. Furthermore, they were washed several times with water during 24 hours in order to remove the formalin solution. Water molecules were later removed using increasing concentrations of alcohol solutions: $70 \%$ for 15 minutes, $80 \%$ for 10 minutes, $90 \%$ for 5 minutes and finally $100 \%$ pure alcohol for 10 minutes. Later on, samples were placed in Xylol and transferred on clean slides after adding Canada balsam. Fnially, Samples covered with the slide cover and left to dry.

Nematodes were first washed with distilled water to dump impurities presented in the samples. Then, they were immersed in lactophenol solution in order to obtain required transparency. Finally, they were mounted on clean glass slide and the covered by nail polish(Al-Jassim, Mahmmod, Salem, \& Al-Jubury, 2017).

Results Analysis: The data resulted from the autopsy of isolated samples were tested and further analyzed using IBM SPSS Statistics version 22.0. The chi-square test $\left(x^{2}\right)$ was used in order to assess the difference in intestinal parasite frequency between groups. The confidence interval was set to be $95 \%$ In all analyses.

\section{RESULTS}

The autopsy and examination results of 25 stray cats (15 males, 10 females) showed that all cats were infected with parasites ( see table 1). The rate of infection with flukes was $12 \%$, cestodes $100 \%$, and nematodes $40 \%$. All these species were isolated from the cats' intestine.

Our diagnosis results showed the presence of ten types of parasitic worms, three of which are trematodes, four of cestodes, and three of nematodes ( see table 2). $48 \%$ of cats acquired infection with the cestodes 
(D.caninum), while $28 \%$ were infected with the ascaris nematode (T.cati).

Moreover, our results showed that cats were infected with more than one type of parasitic worms (see table 3), where eleven cats were infected with one type of such helminthes. The infection percentage reached $44 \%$. Likewise, nine cats were infected with two types of helminthes (the infection rate is $36 \%$ ). Surprisingly, five cats were found to be infected with three or more types of parasitic helminthes, with a percentage of infection of $20 \%$.

Table (4) exhibits the percentages of helminth infections in both male and female cats. The rate of infection with flukes was $8 \%$ in males compared to $4 \%$ in females. In the case of cestodes infection, the percentage of infection in males was higher than that of females, reaching around $60 \%$ compared to $40 \%$. Similarly, in the case of nematode infection, the percentage of infection in males was also higher than in females. It was $28 \%$ for males compared to $12 \%$ for females.

Table (1). Percentage of helminth infection in stray cats in Kirkuk city

\begin{tabular}{|l|l|l|}
\hline Helminthes & $\begin{array}{l}\text { No. of infested / } \\
\text { No. of examined }\end{array}$ & $\%$ Prevalence \\
\hline Trematodes & $3 / 25$ & 12 \\
\hline Cestodes & $25 / 25$ & 100 \\
\hline Nematodes & $10 / 25$ & 40 \\
\hline Total & $25 / 25$ & 100 \\
\hline
\end{tabular}

Table (2). Percentage of total infection with parasitic worms in stray cats in Kirkuk city.

\begin{tabular}{|l|l|l|}
\hline Helminthes & $\begin{array}{l}\text { Number of infected } \\
\text { cats }\end{array}$ & $\begin{array}{l}\% \\
\text { Prevalence }\end{array}$ \\
\hline Trematodes & 3 & 12 \\
Echinochasmus sp. & 1 & 4 \\
Heterophyes sp. & 1 & 4 \\
Prohemistomum sp. & 1 & 4 \\
\hline Cestodes & 25 & 100 \\
Diplopylidium sp. & 6 & 24 \\
Dipylidium caninum & 12 & 48 \\
Joyeuxilla sp. & 4 & 16 \\
Taenia taeniformis & 3 & 12 \\
\hline Nematodes & 10 & 40 \\
Physaloptera & 1 & 4 \\
praeputalis & 7 & 28 \\
Toxocara cati & 2 & 8 \\
Toxoascaris leonine & & \\
\hline
\end{tabular}

Table (3). Percentage of infection and type of infection with parasitic worms in stray cats in Kirkuk city

\begin{tabular}{|l|l|l|}
\hline Infection & Infected cats & \\
\hline Single infection: & & $\%$ Prevalence \\
Trematodes & 0 & 0 \\
Cestodes & 44 & 11 \\
Nematodes & 0 & 0 \\
Total & 44 & 11 \\
\hline Double infection: & & \\
Trematodes & 4 & 1 \\
+Cestodes & 0 & 0 \\
Trematodes+ & 32 & 8 \\
Nematodes & 36 & 9 \\
Cestodes+ & & \\
nematodes & & \\
Total & & 5 \\
\hline Multiple infection & 20 & \\
\hline
\end{tabular}

Table (4). Percentage of helminth infection in males and females stray cats in Kirkuk city.

\begin{tabular}{|l|l|l|l|l|l|l|}
\hline Helminthes & \multicolumn{2}{|l|}{ Infected males } & \multicolumn{2}{l|}{$\begin{array}{l}\text { Infected } \\
\text { females }\end{array}$} & \multicolumn{2}{l|}{ Total } \\
\cline { 2 - 7 } & No. & $\begin{array}{l}\% \\
\text { Prevalen } \\
\text { ce }\end{array}$ & $\begin{array}{l}\text { No. } \\
\text { ( }\end{array}$ & $\begin{array}{l}\% \\
\text { Prevale } \\
\text { nce }\end{array}$ & No. & $\begin{array}{l}\% \\
\text { Prevalence }\end{array}$ \\
\hline $\begin{array}{l}\text { Trematode } \\
\text { s }\end{array}$ & 2 & 8 & 1 & 4 & 3 & 12 \\
\hline Cestodes & 15 & 60 & 10 & 40 & 25 & 100 \\
\hline Nematodes & 7 & 28 & 3 & 12 & 10 & 40 \\
\hline
\end{tabular}

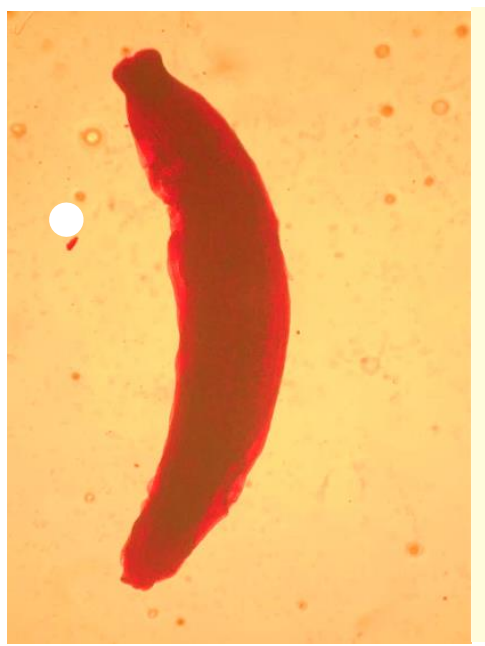

Figure 1.. Echinochasmus sp. 20X
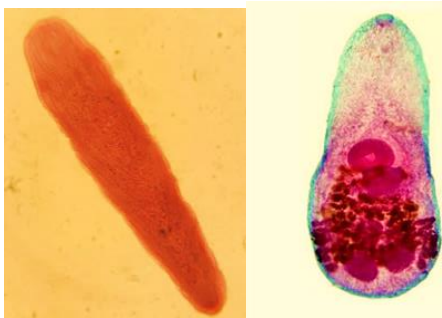

Heterophyes sp. 10X Figure 2.

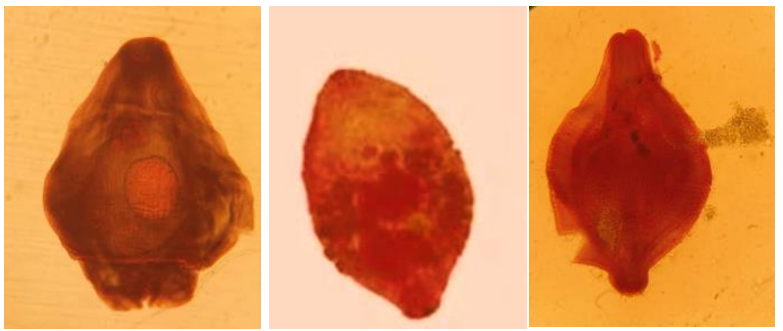

Prohemistomum sp. 10X Figure 3.

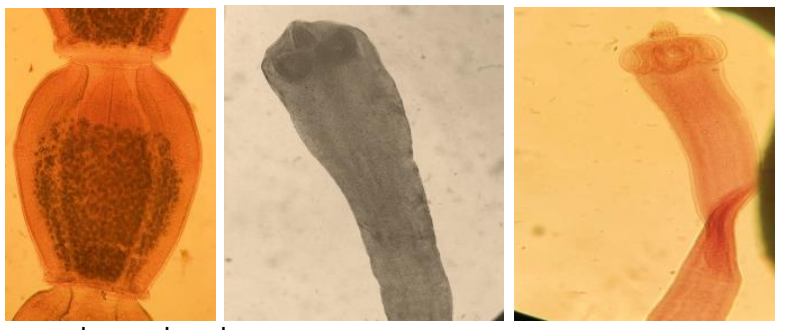

a: scolex and suckers

b: scolex and suckers

proglotides segments c: 


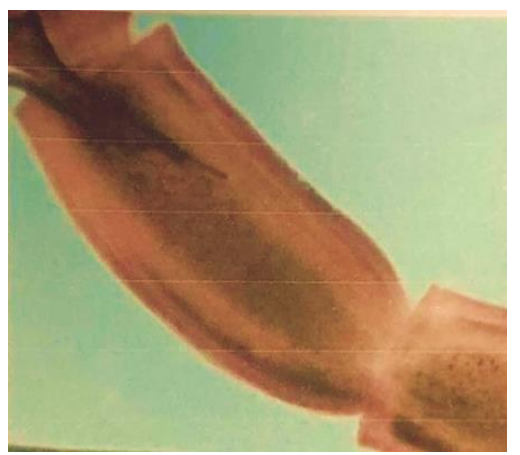

d: mature segments

Diplopylidium at 10X Figure 4. Different parts of

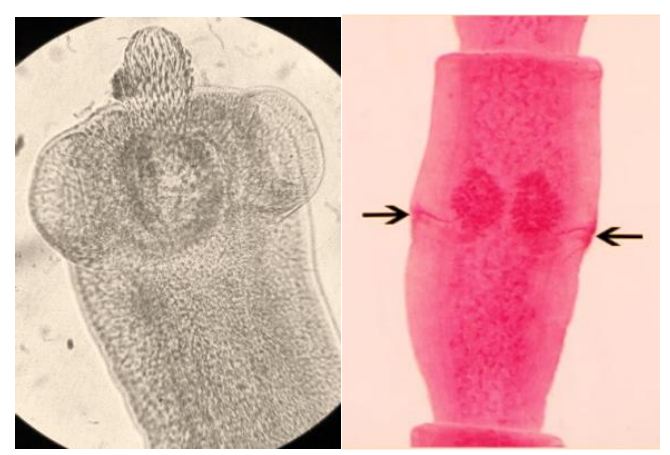

a: scolex and suckers genitals b:

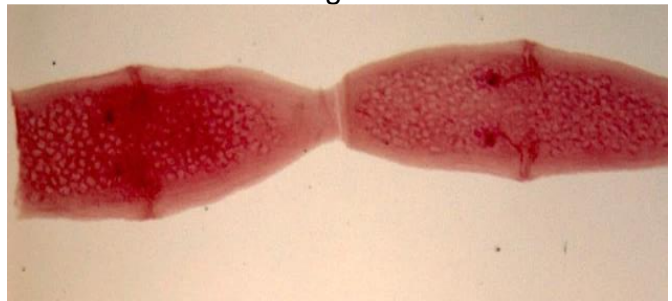

c: Mature segments

10X Figure 5. Dipylidium caninum

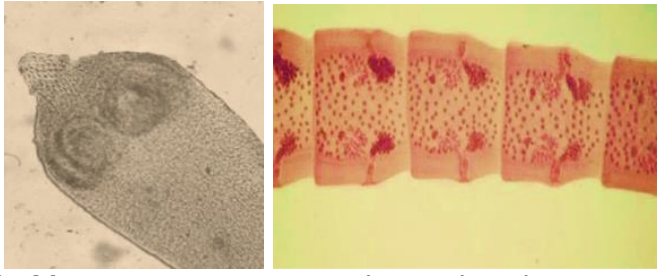

$\mathrm{b}$ : Mature segments a: scolex and suckers 10X Figure 6. Joyexiella pasqualei at

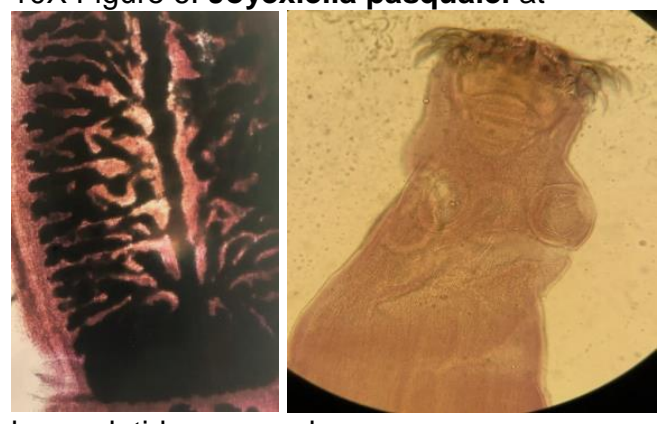

b: proglotides a: scolex

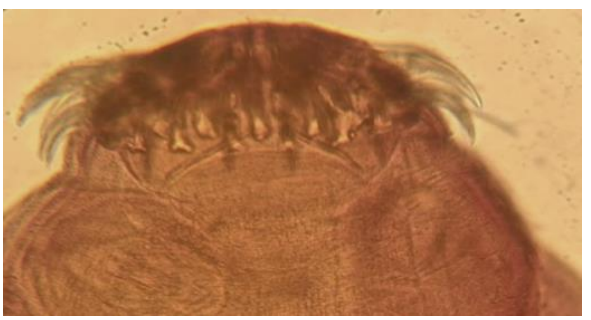

c: hooks and suckers

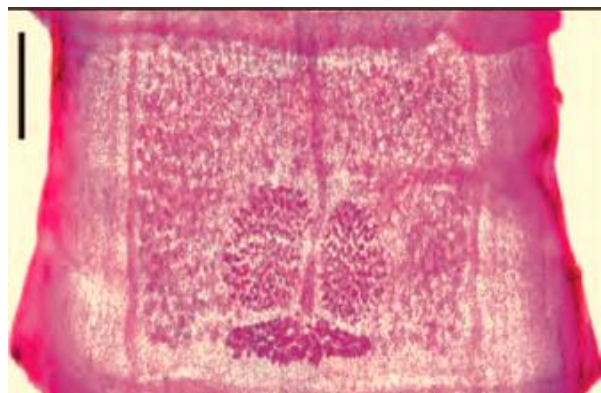

d: Mature segments

10X Figure 7. T.taeniaformis

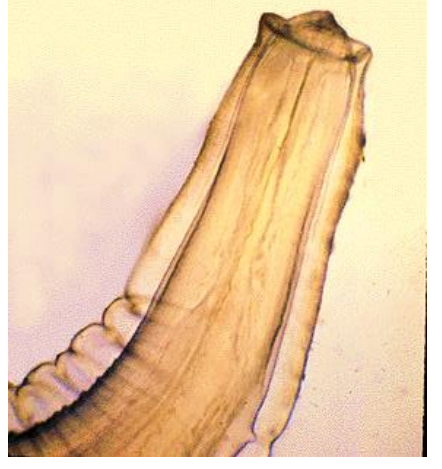

10X Figure 8. The anterior end of Physaloptera praeputalis

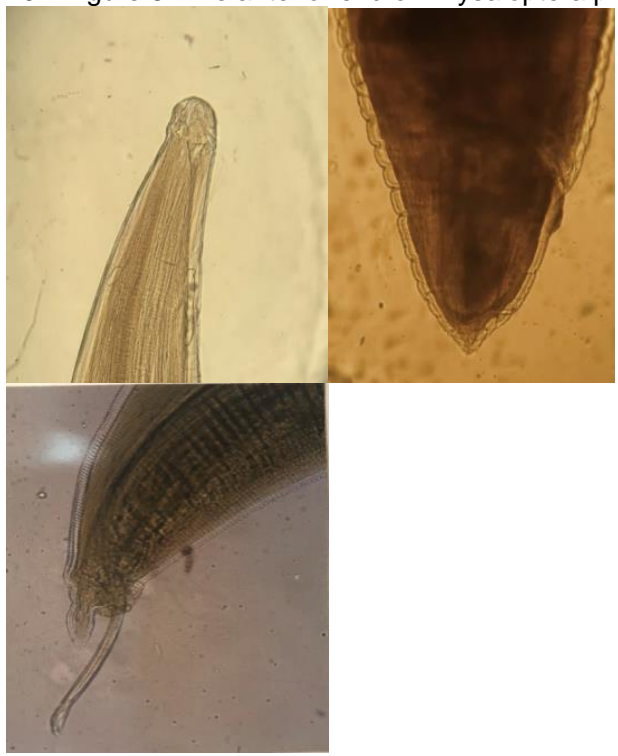

a: anterior end $10 \mathrm{X}$

$\mathrm{b}$ : posterior end of female $10 \mathrm{X}$

c: posterior end of male $10 \mathrm{X}$ 


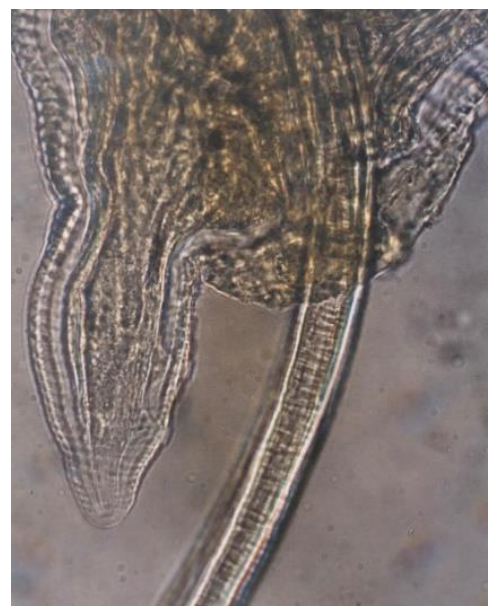

D: Posterior end of male 40X

Figure 9. Toxocara cati

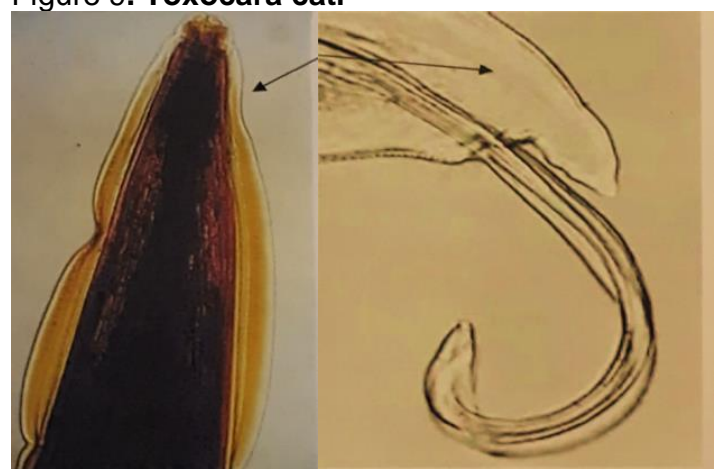

b: anterior end 10X a: posterior end of male 40X Figure 9.

Toxoascaris leonine

\section{DISCUSSION}

Our results clearly demonstrated that helminth infection is widespread among cats in the city of Kirkuk. Eventually, number of these parasites can infect humans as well as their pets. The results showed that every single investigated cat is infected by at least one type of helminthes. Therefore, depending on the sample which we have chosen, the infection rate of stray cats in the city of Kirkuk is almost $100 \%$. Such results is similar to that found by Nasser et al. (Nasser, 2016), where 96\% of cats in the city of Al-Qadisiyah were found to be infected with two or more types of internal or external parasites. The percentage of infection obtained in our study appears to be higher that obtained in other studies for cats in Tikrit (Mohamed, 2005), Babil (al Rammahi, 2014), Diwaniyah (Al-Aredhi, 2015) and Baghdad (Al-Rubaie, Mhaisen, \& AlTae, 2015). The reason for the fluctuation in the infection rates could be due to the difference in the quality of food consumed by cats, in addition to the difference in cats' age. Furthermore, the difficulties of dealing with cats, since most studies limit its investigation to the feces of these cats which could lead to such disparity and disparity in the proportions of the sluff in parasites. Moreover, the reason for the high rate of infection in our study could be due to the large number of stray cats that play an important role in spreading the eggs of parasites in the soil, as cats tend to leave their feces buried under the soil, which can develop to the stage of infection, thus providing opportunities to resmoth the cats as natural precursors to the parasite. The availability of these eggs in the soil will be conducive to infecting rodents, mice and insects. Since cats depend on such hosts to meet their food needs, these small animals are hosts that transmit many parasitic worms.

The current study also showed that the prevalence of parasites in male cats is higher than that in females. This result is consistent with what was found in reference (Nasser, 2016), as it showed that there were no significant differences between infection rate of males and females as a result of the absence of any differences in the quality and quantity of food consumed by cats, since such cats try to feed themselves here and according to what is available in their area. Sometimes they feed on rodents, insects and others creatures, in addition to waste. In this case, they are vulnerable to infection, as these animals are hosts to many parasitic worms. Nonetheless, the results of this current study did not agree with the findings of (Kumsa \& Mekonnen, 2011) and (Hajipour et al., 2015), where they indicated that the prevalence of parasites in females is higher than that in males. The reason for that could be due to the fact that females cannot be examined in an accurate manner, as a result of alternating physiological conditions such as pregnancy, lactation and childbirth, in addition to hormonal change which makes them more susceptible to infection.

The reason for infection with more than one type of parasite is due to the fact that cats are abundant in large numbers in the city of Kirkuk. They are among the animals that feed on garbage. Moreover, the increase in the number of cats that roam the streets in city of Kirkuk, with the delay of the municipality in transporting waste before cats tamper with it. This clearly exhibits the danger that the residents can be exposed to in the city of Kirkuk, which calls for a wide campaign by the health, veterinary and municipal departments to eliminate these animals and expedite the removal of waste from the streets, as well as pest control campaigns.

The current study is the first of its kind to record Echinochasmus (Figure 1), Heterophyes (Figure 2), and Prohemistomum (Figure 3 ) in stray cats in the Iraq. This could be a result of dumping the internal guts of fish by street vendors in dirt containers around residential homes before the municipality transported them to recycling stations. This could be the reason for the wide spread of infection among stray cats,where fish can act as intermediate hosts for these foraminifera and thus are a source of infection. Such result was not indicated in any previous study. Several types of Heterophytes were found from domestic cats in different regions of Egypt (Abuzeid, Youssef, Aal, \& El-Gawady, 2016; El-Dakhly \& Gharib, 2017). The infection rate reported in our study of the Prohemistomum parasite is higher than that reported by ElDakhly et al. (El-Dakhly \& Gharib, 2017) which was 1.6\%, close to that reported by Abuzeid el al. which amounted to 4\% (Abuzeid, Youssef, Aal, \& El-Gawady, 2015). Most of these identified species are parasites of zoonotic origin. They are transformed by eating raw meat from freshwater or saltwater fish. Therefore, cats and stray animals play an important role as staging hosts (Chai, Bahk, \& Sohn, 2013). 
For the infection with Cestoda, our results showed that the percentage of infection with the tapeworm Diplopylidium caninum (Figure 4) is close to that reported in reference (Nasser, 2016). In that study, the researcher scan the infection by internal parasites in domestic cats in Al-Qadisiyah city. The infection rate was around $21 \%$, which is different than that reported in Baghdad area (51\%) (Al-Rubaie, et al., 2015). In another studies (Daoud, AlTae, \& Salman, 1988), the percentage of infections was $34 \%, 45 \%, 45 \%$, in Baghdad, Kirkuk and Najaf, respectively. Compared to Qatar the percentage of infection is about $47 \%$ (M. A. Abu-Madi, J. M. Behnke, K. S. Prabhaker, R. Al-lbrahim, \& J. W. Lewis, 2010). The reason for the varying rates of infection could be due to the availability of intermediate hosts. Since the worm uses insects as a primary intermediate host and reptiles as a secondary intermediate host. Henece, the availability of these insects leads to an increase in the infection rate by parasite. Cats may not pose any threat to other animals because the larvae must pass through the faecal-eating insects.

Concerning the canine tapeworm Dipylidium caninum (Figure 5), the results were different from those of (Hassan \& Barzinji, 2018), in which they investigated the infection by the intestinal parasites in cats and dogs in the city of Kirkuk. The infection rate of this parasite was $16.8 \%$, it was similar to that reported in the study of (Al-Obaidi, 2012; AlRubaie, et al., 2015), where it reached $64 \%$ and $43 \%$, respectively. This difference in infection rates may be due to the availability of intermediate hosts such as fleas, lice and the larvae of flies. Thus, cats and dogs are infected when feeding on these insects, and then the infection is transmitted to humans through water and food contaminated with the feces of cats and dogs containing eggs (Beugnet, Labuschagne, Vos, Crafford, \& Fourie, 2018). The infection rate caused by the Joyeuxilla sp. (Figure 6) was inconsistent with that reported by (AlRubaie, et al., 2015) as it reached 58\%. The reason can be attributed to the quality of food and the availability of the intermediate host in the places where the cats are.

The rate of infection of stray cats with Taenia taeniformis (Figure 7) was close to that recorded by (Daoud, et al., 1988) in Baghdad (11\%), and more than that reported in Kirkuk and Najaf, which amounted to $5 \%$ in each of them. While this ratew was less than that reported by (al Rammahi, 2014) in urban and rural areas from the city of Babylon, which amounted to $31.2 \%$ and $32 \%$, respectively, and is closer to what was reported by (Hassan \& Barzinji, 2018), which amounted to $14.58 \%$. It is higher than that reported by (El-Dakhly \& Gharib, 2017) in Egypt, which was $9.6 \%$.

Three types of nematodes have been identified. In this study, the infection rate of cats with the nematode Physaloptera praeputalis (Figure 8 ) is close to that reported by J. Lewis et al. (M. Abu-Madi, J. Behnke, K. S. Prabhaker, R. Al-Ibrahim, \& J. Lewis, 2010) in Qatar ( 5\%), but samller than that indicated by Rubaie et al. in Baghdad (Al-Rubaie, et al., 2015), Kirkuk and Najaf (Daoud, et al., 1988) and in Al-Mosul (Al-Obaidi, 2012), which was ranging between $30 \%-70 \%$. The reason for such high infection rate could be attributed to the environmental conditions that allow the availability of intermediate hosts, such as arthropods (crickets), for continuation of the parasite's life cycle (Quadros, Marques, Marques, Moura, \& Antonelli, 2014). Of course such infections occure rarely, only upon digestion of the host.

For the cat worm Ascaris Toxocara cati (Figure.9), the infection rate was close to that reported in Kirkuk (Hassan \& Barzinji, 2018) and in Qadisiyah (Nasser, 2016), but higher than that in Baghdad (A. Hadi \& Faraj, 2014). It reached the value of $5 \%$ smaller than that reported in the litelatures (Al-Aredhi, 2015; Al-Rubaie, et al., 2015; al Rammahi, 2014; Quadros, et al., 2014), which amounted to $24 \%-40 \%$. The reason for the difference in the infection rate could be due to the environmental conditions of each area.

For Toxoascaris leonine (Fig. 10), the rate of infection of stray cats was identical to that reported in the city of Kirkuk (Hassan \& Barzinji, 2018).

\section{REFERENCES}

1. Abu-Madi, M., Behnke, J., Prabhaker, K. S., Al-Ibrahim, R., \& Lewis, J. (2010). Intestinal helminths of feral cat populations from urban and suburban districts of Qatar. Veterinary parasitology, 168, 284-292.

2. Abu-Madi, M. A., Behnke, J. M., Prabhaker, K .S., AlIbrahim, R., \& Lewis, J. W. (2010). Intestinal helminths of feral cat populations from urban and suburban districts of Qatar. Veterinary Parasitology, 168(3), 284-292.

3. Abuzeid, A., Youssef, E., Aal, A., \& El-Gawady, H. (2016). Studies on the trematode parasites of stray dogs in Egypt. $J$ Bacteriol Parasitol, 7, 3.

4. Abuzeid, A., Youssef, E., Aal, A., \& El-Gawady, H. (2015). The prevalence of the helminth parasites of stray dogs in Ismailia City. Egyptian Veterinary Medical Society of Parasitology Journal 1687-2274, 11, 103-114.

5. Al-Aredhi, H. (2015). Prevalence of gastrointestinal parasites in domestic cats (Felis catus) in Al-Diwaniya province / Iraq. International Journal of Current Microbiology and Applied Sciences, 4, 166-171.

6. Al-Jassim, K. B. N ,.Mahmmod, Y. S., Salem, Z. M., \& AlJubury, A. (2017). Epidemiological investigation of gastrointestinal parasites in dog populations in Basra province, Southern Iraq. Journal of parasitic diseases : official organ of the Indian Society for Parasitology, 4 ,(4)1 .1013-1006

7. Al-Obaidi, Q. (2012). Prevalence of Internal Helminthes in Stray Cats (Felis Catus) in Mosul City, Mosul-Iraq. Journal of Animal and Veterinary Advances, 11, 2732-2736.

8. Al-Rubaie, A.-R., Mhaisen, F., \& Al-Tae, A.-R. (2015). Survey of Some Gastrointestinal Cestodes and Nematodes from Stray Cats at Baghdad City, Iraq. American Journal of Biology and Life Sciences. Vol. 3, No. 6, 2015, pp. 246-253, 3, 246-253.

9. al Rammahi, H. (2014). Prevalence of intestinal helminthes in feral cats in Babylon province/lraq, urban and rural locations. MRVSA, 3, 1-8.

10. Barbosa, A. d. S., Pereira Bastos, O. M., Uchôa, C. M. A., Pissinatti, A., Filho, P. R. F., Dib, L. V., et al. (2015). Isolation and maintenance of Balantidium coli (Malmsteim, 1857) cultured from fecal samples of pigs and non-human primates. Veterinary Parasitology, 210(3), 240-245.

11. Beugnet, F., Labuschagne, M., Vos, C. d., Crafford, D., \& Fourie, J. (2018). Analysis of Dipylidium caninum tapeworms from dogs and cats, or their respective fleas. /10.1051]parasite/2018029]. Parasite, 25. 
12. Chai, J.-Y., Bahk, Y. Y., \& Sohn, W.-M. (2013). Trematodes Recovered in the Small Intestine of Stray Cats in the Republic of Korea. Korean J Parasitol, 51(1), 99-106.

13. Daoud, I., Al-Tae, A. A., \& Salman, Y. J. (1988 .(Prevalence of gastro-intestinal helminths in cats from Iraq.

14. El-Dakhly, K., \& Gharib, A. (2017). A Preliminary Study on the Helminth Fauna in Necropsied Stray Cats (Felis catus) in Beni-Suef, Egypt. Journal of Advanced Veterinary Rssearch, 7, 87-92.

15. Fisher, M. (2003). <em>Toxocara cati</em>: an underestimated zoonotic agent. Trends in Parasitology, 19(4), 167-170.

16. Hadi, A., \& Faraj, A. A. (2014). ROLE OF DOMESTIC CATS FELIS CATUS AS RESERVOIR HOSTS OF INTERNAL PARASITES AND PROTOZOA IN BAGHDAD.

17. Hadi, M \& ,.Hind Abdulzahra Al, s. (2018). Diagnostic and Identifical study of Turkey (Meleagris gallopavo) Parasites in AL-Diwaniyah province. Al-Qadisiyah Journal Of Pure Science, 22(4.) (

18. Hajipour, N., Keighobadi, M., Minas, A., Abad, R., Golabi, M., \& Badali ,A. (2015). Prevalence of flea infestation in stray cats in North West of Iran, Iran. Biological Forum - An International Journal, 7, 575-580.
19. Hassan, H., \& Barzinji, A. (2018). Epidemiological Survey on Stray Dogs and Cats Gastro-Intestinal Parasites in Kirkuk province, Iraq. Kirkuk University Journal-Scientific Studies, 13, 228-238.

20. Kumsa, B., \& Mekonnen, S. (2011). Ixodid ticks, fleas and lice infesting dogs and cats in Hawassa, southern Ethiopia. The Onderstepoort journal of veterinary research, 78, E1-E4.

21. Ma, G., Holland, C. V., Wang, T., Hofmann, A., Fan, C.-K., Maizels, R. M., et al. (2018). Human toxocariasis. The Lancet Infectious Diseases, 18(1), e14-e24.

22. Mircean, V., Titilincu, A., \& Vasile, C. (2010). Prevalence of endoparasites in household cat (Felis catus) populations from Transylvania (Romania) and association with risk factors. Veterinary parasitology, 171, 163-166.

23. Mohamed, A. A., and Hassan, H. F. and Daoud, I. S. (2005). Toxocara parasites spread in stray cats and dogs in Tikrit. Tikrit Journal of Pure Science, 10(2.)(

24. Nasser, F. H. (2016). F. H. Epidemiological and diagnostic study of external and Internal Parasites in Domestic Cats (Felis catus) in Al-Qadisiyah Province. [ M. Sc. Thesis, Coll. Sci., Univ. AlQadisiya:]. 122.

25. Quadros, R ,.Marques, S., Marques, T., Moura, A., \& Antonelli, M. (2014). First report of the nematode Physaloptera praeputialis parasitizing a jaguarandi. Neotropical Biology and Conservation, 9, 187-190. 